\title{
Effect of microemulsions on transdermal delivery of citalopram: optimization studies using mixture design and response surface methodology
}

This article was published in the following Dove Press journal:

International Journal of Nanomedicine

24 June 2013

Number of times this article has been viewed

\section{Chi-Te Huang' \\ Ming-Jun Tsai ${ }^{2,3}$ \\ Yu-Hsuan Lin' \\ Yaw-Sya Fu ${ }^{4}$ \\ Yaw-Bin Huang 5 \\ Yi-Hung Tsai ${ }^{5}$ \\ Pao-Chu Wu'}

'School of Pharmacy, Kaohsiung Medical University, Kaohsiung City,

${ }^{2}$ Department of Neurology, China Medical University Hospital, Taichung,

${ }^{3}$ School of Medicine, Medical College,

China Medical University, Taichung,

${ }^{4}$ Faculty of Biomedical Science and

Environmental Biology, ${ }^{5}$ Graduate

Institute of Clinical Pharmacy,

Kaohsiung Medical University,

Kaohsiung City, Taiwan, Republic

of China
Correspondence: Pao-Chu Wu School of Pharmacy, Kaohsiung Medical University, 100 Shih-Chuan First Road, Kaohsiung City 807, Taiwan, Republic of China

Tel +88673 I 2 II 0 I ext 2660

Fax +886732I 0683

Email pachwu@kmu.edu.tw
Abstract: The aim of this study was to evaluate the potential of microemulsions as a drug vehicle for transdermal delivery of citalopram. A computerized statistical technique of response surface methodology with mixture design was used to investigate and optimize the influence of the formulation compositions including a mixture of Brij 30/Brij 35 surfactants (at a ratio of $4: 1,20 \%-30 \%)$, isopropyl alcohol $(20 \%-30 \%)$, and distilled water $(40 \%-50 \%)$ on the properties of the drug-loaded microemulsions, including permeation rate (flux) and lag time. When microemulsions were used as a vehicle, the drug permeation rate increased significantly and the lag time shortened significantly when compared with the aqueous control of $40 \%$ isopropyl alcohol solution containing 3\% citalopram, demonstrating that microemulsions are a promising vehicle for transdermal application. With regard to the pharmacokinetic parameters of citalopram, the flux required for the transdermal delivery system was about $1280 \mu \mathrm{g}$ per hour. The microemulsions loaded with citalopram $3 \%$ and $10 \%$ showed respective flux rates of $179.6 \mu \mathrm{g} / \mathrm{cm}^{2}$ and $513.8 \mu \mathrm{g} / \mathrm{cm}^{2}$ per hour, indicating that the study formulation could provide effective therapeutic concentrations over a practical application area. The animal study showed that the optimized formulation (F15) containing 3\% citalopram with an application area of $3.46 \mathrm{~cm}^{2}$ is able to reach a minimum effective therapeutic concentration with no erythematous reaction.

Keywords: citalopram, microemulsion, transdermal delivery systems

\section{Introduction}

Citalopram (1-[3-(dimethylamino)propyl]-1-(4-fluorophenyl)-1,3-dihydro-5-isobenzofurancar bonitrile, $\mathrm{C}_{20} \mathrm{H}_{21} \mathrm{FN}_{2} \mathrm{O}$ ) is a selective serotonin re-uptake inhibitor with a molecular weight of $324.40 \mathrm{~g} / \mathrm{mol}$ and a pKa of 9.59. It was approved by the US Food and Drug Administration in 1998 to treat the symptoms of major depression. ${ }^{1-3}$ In the clinical setting, citalopram is used alone or in combination with other antidepressant and/or antipsychotic drugs to treat a variety of psychiatric disorders. ${ }^{4}$ Citalopram is available as $10 \mathrm{mg}, 20 \mathrm{mg}$, and $40 \mathrm{mg}$ tablets. The recommended starting dose is $20 \mathrm{mg}$ / day, with a maximum dose of $40 \mathrm{mg} /$ day. After oral administration, the most common gastrointestinal side effects are nausea (21\%) and xerostomia (20\%). The nausea is caused when the $5 \mathrm{HT} 3$ receptors are activated by serotonin, when the receptor is exhibited in the digestive tract. 5HT3 receptors also stimulate vomiting, and the dose administered must be adjusted when this occurs. ${ }^{5,6}$ There has been a recent clinical report of subacute cutaneous lupus erythematosus caused by oral citalopram, highlighting that the indication for and dose of citalopram must be monitored carefully. ${ }^{7}$

There has been little research to date on transdermal antidepressants. However, several reports suggest the potential application and advantages of antidepressants 
administered via the transdermal route. ${ }^{8-10} \mathrm{~A}$ transdermal drug delivery system able to bypass the gastrointestinal tract may be a suitable administration route for citalopram to avoid gastrointestinal side effects. Moreover, citalopram has a low molecular weight and the daily dose needed is small, which makes it a promising candidate for transdermal delivery. The stratum corneum is a major obstacle in the transport of a foreign compound in a transdermal delivery system. In the past decade, numerous strategies have been investigated for their ability to increase drug permeation capacity through the skin, including vehicles, chemical penetration enhancers, iontophoresis, electroporation, ultrasound, and microneedle technologies, used alone or in combination. ${ }^{11-15}$ In recent years, ethosomes, microemulsions, liposomes, and polymeric nanoparticles have shown potential as drug vehicles in modifying the properties of therapeutic agents and in improving their transport through the skin. ${ }^{16-21}$

Microemulsions are optically isotropic and thermodynamically stable colloidal systems. Droplet size is typically in the range of $10-100 \mathrm{~nm} .{ }^{22-24}$ They are typically composed of an aqueous phase, oil phase, surfactant, and cosurfactant. Microemulsions can be prepared by spontaneous emulsification, which offers several advantages over other drug vehicles, such as liposome and polymeric nanoparticles, including lower preparation costs, high drug loading, no need for an organic solvent, and a long shelf-life for both hydrophilic and lipophilic therapeutic agents. ${ }^{16-25}$ Numerous studies have demonstrated that microemulsions can improve drug transport through the skin compared with conventional topical preparations, such as gels, creams, and ointments. ${ }^{26-29}$ Hence, microemulsions were used as the vehicle for transdermal delivery of citalopram in the present study.

Obtaining an optimal transdermal formulation with the appropriate properties of a high permeation rate, a shortened lag time, and minimal requirement for experimental investigation is an important issue in the development of a pharmaceutical formulation. A statistical optimization tool based on response surface methodology and experimental formulations, such as central composite, Box-Behnken, factorial, and mixture designs, ${ }^{16,30-36}$ has been used widely, because it can evaluate the main effects and interaction of all variables simultaneously. Hence, response surface methodology with a constrained mixture design was used to develop an optimal citalopram-loaded microemulsion for topical application, and the effect of composition of the microemulsion on the ability of citalopram to permeate rat skin was investigated.

\section{Materials and methods Materials}

Citalopram hydrobromide was purchased from Arch Pharmalabs Ltd (Mumbai, India). Verapamil chloride was purchased from Sigma-Aldrich (St Louis, MO, USA). Polyoxyl 23 lauryl ether (Brij 35) and polyoxyl 4 lauryl ether (Brij 30) were sourced from Acros Organics (Fair Lawn, NJ, USA). Isopropyl myristate and isopropyl alcohol were purchased from Merck Chemicals (Darmstadt, Germany). All other chemicals and solvents were of analytical reagent grade.

\section{Construction of phase diagrams}

Phase diagrams were constructed using the water titration method to obtain the level range of each component for the existence range of microemulsions. A surfactant mixture of Brij 30/Brij 35 at a ratio of 4:1, isopropyl myristate, and aqueous solution containing $40 \%$ cosurfactant including isopropyl alcohol, propylene glycol, and poly(ethylene glycol) (PEG) 400 were used. Mixtures of oil phase and the mixed surfactants were diluted at defined weight ratios $(1 / 9,2 / 8$, $3 / 7,4 / 6,5 / 5,6 / 4,7 / 3,8 / 2,9 / 1)$ with aqueous phase dropwise under agitation until the mixture became clear. The amounts of components used were recorded to complete the phase diagrams.

\section{Preparation of citalopram-loaded microemulsions}

A constrained mixture design ${ }^{37}$ consisting of three independent variables was used in this study to prepare model citalopram-loaded microemulsions. The oil phase was fixed at $10 \%$ because citalopram is a hydrophilic compound. The effect of the amount of oil on drug solubility in the microemulsion was negligible. The amounts of mixed surfactants, isopropyl alcohol, and double-distilled water were used as independent variables. The range of independent variables was selected according to the phase diagrams. The total amount of the varying excipients was maintained at $90 \%$ of the total amount of the formulation. Based on the constrained mixture model (Design-Expert ${ }^{\circledR}$ software, Stat-Ease Corporation, Minneapolis, MN, USA), 14 citalopram-loaded model microemulsions were arranged randomly. The compositions of these citalopram-loaded microemulsions are listed in Table 1. The mixed Brij 30/ Brij 35 surfactant was prepared in advance at a ratio of 4:1. The isopropyl myristate and aqueous phases containing cosurfactant were incorporated into the mixed surfactant in order, and shaken for one minute at each step. All microemulsions became transparent. Citalopram 3\%-10\% 
Table I Composition, physiochemical properties, and permeability parameters of citalopram-loaded model microemulsions

\begin{tabular}{|c|c|c|c|c|c|c|c|c|}
\hline & $x_{1}$ & $X_{2}$ & $\mathbf{x}_{3}$ & Size $(n m)$ & PI & $\begin{array}{l}\text { Viscosity } \\
\left(\operatorname{cps} \times 10^{3}\right)\end{array}$ & $\begin{array}{l}\text { Flux } \\
\left(\mu \mathrm{g} / \mathrm{cm}^{2} / \mathrm{h}\right)\end{array}$ & LT (h) \\
\hline FOI & 23.3 & 23.3 & 43.3 & $13.9 \pm 0.7$ & $0.39 \pm 0.18$ & $10.23 \pm 0.06$ & $163.8 \pm 4.5$ & $1.3 \pm 0.6$ \\
\hline F02 & 21.7 & 26.7 & 41.7 & $16.0 \pm 2.0$ & $0.38 \pm 0.13$ & $8.9 \pm 0.07$ & $161.5 \pm 6.8$ & $1.0 \pm 0.0$ \\
\hline F03 & 20.0 & 30.0 & 40.0 & $16.5 \pm 0.1$ & $0.47 \pm 0.04$ & $7.53 \pm 0.06$ & $165.0 \pm 20.7$ & $0.8 \pm 0.3$ \\
\hline F04 & 25.0 & 25.0 & 40.0 & $38.0 \pm 10.5$ & $0.43 \pm 0.10$ & $9.80 \pm 0.10$ & $172.1 \pm 14.1$ & $2.0 \pm 0.0$ \\
\hline F05 & 20.0 & 20.0 & 50.0 & $19.9 \pm 3.7$ & $0.30 \pm 0.15$ & $10.73 \pm 0.12$ & $153.8 \pm 16.1$ & $1.2 \pm 0.8$ \\
\hline F06 & 20.0 & 30.0 & 40.0 & $17.3 \pm 2.4$ & $0.43 \pm 0.12$ & $7.08 \pm 0.07$ & $179.8 \pm 11.8$ & $1.5 \pm 0.9$ \\
\hline F07 & 20.0 & 20.0 & 50.0 & $17.7 \pm 3.2$ & $0.33 \pm 0.18$ & $10.17 \pm 0.06$ & $179.8 \pm 18.1$ & $1.7 \pm 0.6$ \\
\hline F08 & 25.0 & 25.0 & 40.0 & $20.8 \pm 6.4$ & $0.36 \pm 0.09$ & $9.22 \pm 0.04$ & $176.8 \pm 15.9$ & $1.7 \pm 0.6$ \\
\hline F09 & 30.0 & 20.0 & 40.0 & $18.5 \pm 10.7$ & $0.44 \pm 0.10$ & $13.07 \pm 0.06$ & $191.8 \pm 14.6$ & $2.7 \pm 0.6$ \\
\hline FIO & 21.7 & 21.7 & 46.7 & $14.5 \pm 0.5$ & $0.33 \pm 0.01$ & $10.23 \pm 0.06$ & $188.6 \pm 13.4$ & $2.3 \pm 0.6$ \\
\hline FII & 30.0 & 20.0 & 40.0 & $32.1 \pm 5.5$ & $0.34 \pm 0.05$ & $12.70 \pm 0.00$ & $216.1 \pm 11.0$ & $2.7 \pm 0.6$ \\
\hline $\mathrm{FI} 2$ & 25.0 & 20.0 & 45.0 & $13.5 \pm 0.2$ & $0.45 \pm 0.09$ & $12.00 \pm 0.10$ & $211.0 \pm 8.1$ & $3.0 \pm 0.0$ \\
\hline $\mathrm{FI} 3$ & 26.7 & 21.7 & 41.7 & $13.2 \pm 0.1$ & $0.45 \pm 0.09$ & $11.30 \pm 0.10$ & $221.5 \pm 8.9$ & $2.7 \pm 0.6$ \\
\hline FI4 & 20.0 & 25.0 & 45.0 & $13.2 \pm 0.1$ & $0.36 \pm 0.14$ & $9.52 \pm 0.10$ & $245.6 \pm 14.0$ & $2.7 \pm 0.6$ \\
\hline
\end{tabular}

Notes: Amount of citalopram and isopropyl myristate was fixed at $300 \mathrm{mg}$ and I.0 g, respectively; total amount of three variables of $X_{1}(\mathrm{Brij} 30 / \mathrm{Brij} 35=4 / \mathrm{I}, 20 \%-30 \%$ ), $X_{2}$ (isopropyl alcohol $20 \%-30 \%$ ), and $X_{3}$ (distilled water, $40 \%-50 \%$ ) was $9.0 \mathrm{~g} \mathrm{X}_{1}+\mathrm{X}_{2}+\mathrm{X}_{3}=1$.

Abbreviations: $\mathrm{LT}$, lag time; $\mathrm{Pl}$, polydispersity index.

was dissolved in the final microemulsion formulations. No precipitation was observed.

\section{Characterization of microemulsions}

A cone-plate viscometer (Model LVDV-II, Brookfield Engineering Laboratories, Middleboro, MA, USA) was used to determine the viscosity of the citalopram-loaded microemulsions. Five milliliters of sample was loaded into the plate, and the temperature was maintained at $37^{\circ} \mathrm{C}$ for 3 minutes using a thermostatic water pump. The rotation rate was set at $120 \mathrm{rpm}$. Readings were taken 20 seconds after measurement was started. Each datum point represents the average of three determinations.

A photocorrelation spectroscope equipped with laser light scattering (Zetasizer 3000HSA, Malvern Instruments, Malvern, UK) was used to measure the droplet sizes in the citalopram-loaded microemulsions. The helium-neon laser was set at $633 \mathrm{~nm}$. A $50 \mu \mathrm{L}$ sample was diluted in distilled water to $3 \mathrm{~mL}$, loaded into a cuvette, and placed in the scattering chamber at room temperature. Light scattering was set at a fixed angle of $90^{\circ}$.

\section{Skin permeation study}

The ability of citalopram in the various microemulsions to permeate skin was determined using a modified Franz diffusion cell. Abdominal skin excised from a Wistar rat (275-300 g) was mounted between the receptor cell and donor cell with the stratum corneum facing upwards. The effective diffusion area of the cell was $3.46 \mathrm{~cm}^{2}$. The donor cell was loaded with $1 \mathrm{~mL}$ samples of the citalopram microemulsions and occluded by Parafilm ${ }^{\circledR}$ (Pechiney Plastic Packaging Company, Chicago, IL, USA). The receptor cell was filled with $20 \mathrm{~mL}$ of phosphate buffer $(0.05 \mathrm{M}, \mathrm{pH} 7.4)$, and its temperature was maintained at $37^{\circ} \mathrm{C} \pm 0.5^{\circ} \mathrm{C}$ during the experiment. At specific intervals, $500 \mu \mathrm{L}$ of receptor medium was withdrawn and analyzed using high-pressure liquid chromatography. ${ }^{38} \mathrm{All}$ experiments were repeated three times and averaged. The skin permeation protocol was approved by the Institutional Animal Care and Use Committee of Kaohsiung Medical University. The committee confirmed that the permeation experiment followed the guidelines set out by the Guide for Laboratory Fact Lines and Care.

\section{In vivo animal study}

Male Wistar rats weighing 250-275 g were anesthetized throughout the study using urethane 25\% (Sigma-Aldrich) given as an intraperitoneal injection $(0.33 \mu \mathrm{L}$ per $\mathrm{mg}$ of rat body weight before the study). Glass cylinders, each with an available area of $3.46 \mathrm{~cm}^{2}$, were glued onto rat abdominal skin. Next, $1 \mathrm{~mL}$ of each microemulsion formulation was added to a cylinder. Blood samples $(0.5 \mathrm{~mL})$ were drawn from the jugular vein at each sampling time. The methods used to prepare the samples were modified from those used in a previous study, ${ }^{39}$ ie, a $150 \mu \mathrm{L}$ plasma sample was added to $50 \mu \mathrm{L}$ of verapamil as the internal standard and vortexed for 2 minutes, then added to $600 \mu \mathrm{L}$ of methanol and vortexed for a further 2 minutes. The mixtures were centrifuged at $2500 \mathrm{~g}$ for 5 minutes to spin down the protein aggregates. The supernatants were then analyzed by high-pressure liquid chromatography. 


\section{Skin erythema study}

Glass cylinders with an available area of $2.42 \mathrm{~cm}^{2}$ were glued onto rat abdominal skin, and a $1 \mathrm{~mL}$ sample of each microemulsion formulations was added to each cylinder. The formulation were moved at the sampling point and the rat skins were examined using a chroma meter (MiniScan ${ }^{\circledR}$ XE Plus, HunterLab, Reston, VA, USA). The color reflectance of the rat skin was recorded as Commission Internationale de l'Eclairage (CIE) in three-dimensions ( $\mathrm{L}^{*}$ for $\mathrm{a}^{*}, \mathrm{~b}^{*}$ ). A defined area near the treated site was designated as the control. ${ }^{40}$

\section{Chromatographic conditions}

An L-7100 series high-pressure liquid chromatography system (Hitachi, Tokyo, Japan) and a Supelco Discovery ${ }^{\circledR}$ Bio Wide Pore C5 column $(150 \times 4.6 \mathrm{~mm}$ ID, particle size $5 \mu \mathrm{m}$, SigmaAldrich) were used for analysis of the citalopram concentration and modified from a previously reported method. ${ }^{3}$ A mixture of $0.025 \mathrm{M}$ potassium dihydrogen phosphate and acetonitrile at a ratio of $60: 40(\mathrm{v} / \mathrm{v})$ was used as the mobile phase. The flow rate was set at $1 \mathrm{~mL}$ per minute. The detection wavelength was set at $237 \mathrm{~nm}$. Verapamil $300 \mu \mathrm{g} / \mathrm{mL}$ was used as the internal standard. The citalopram concentration ranged from $5 \mu \mathrm{g} / \mathrm{mL}$ to $1000 \mu \mathrm{g} / \mathrm{mL}$ with linearity $\left(r^{2}=0.9993\right)$. The limit of quantitation was $1 \mu \mathrm{g} / \mathrm{mL}$. For the in vivo animal study, the plasma concentration was measured by fluorescence detection modified from a previous method. ${ }^{39}$ An L-2480 series fluorescence detector (Hitachi) and a Supelco Discovery Bio Wide Pore C5 column (Sigma-Aldrich) were used. The excitation wavelength was $249 \mathrm{~nm}$, and the emission wavelength was $302 \mathrm{~nm}$. The in vivo concentration of citalopram ranged from $5 \mathrm{ng} / \mathrm{mL}$ to $500 \mathrm{ng} / \mathrm{mL}$ with linearity $\left(r^{2}=0.9999\right)$. The limit of quantitation was $1 \mathrm{ng} / \mathrm{mL}$.

\section{Data analysis}

The cumulative amount of citalopram transported across rat skin was plotted as a function of time. The slopes of the resulting linear plots in the steady state were calculated, and the permeation rate (flux) was determined from the slope. Time to first detection of the drug was selected as the lag time. The independent variables $\left(\mathrm{X}_{1}, \mathrm{X}_{2}\right.$, and $\left.\mathrm{X}_{3}\right)$ and responses (flux and lag time) of all model citalopram-loaded microemulsions were analyzed using Design-Expert ${ }^{\circledR}$ software (Stat-Ease Corporation). Polynomial linear, quadratic, and cubic equations were used to show the relationship between the independent variables and responses. Statistical parameters, including the multiple correlation coefficient $\left(\mathrm{R}^{2}\right)$, adjusted multiple correlation coefficient (adjusted $\mathrm{R}^{2}$ ), coefficient of variation, $P$ value for the model $(<0.05)$, and $P$ value for lack of fit $(>0.05)$ validated by Design-Expert software (Stat-Ease Corporation) were used to select the model equation with best fit.

\section{Results and discussion Pseudoternary phase diagrams}

The excipients used to prepare the microemulsions were pharmaceutically accepted ingredients. Isopropyl myristate is used widely as a nongreasy emollient and emulsifying agent
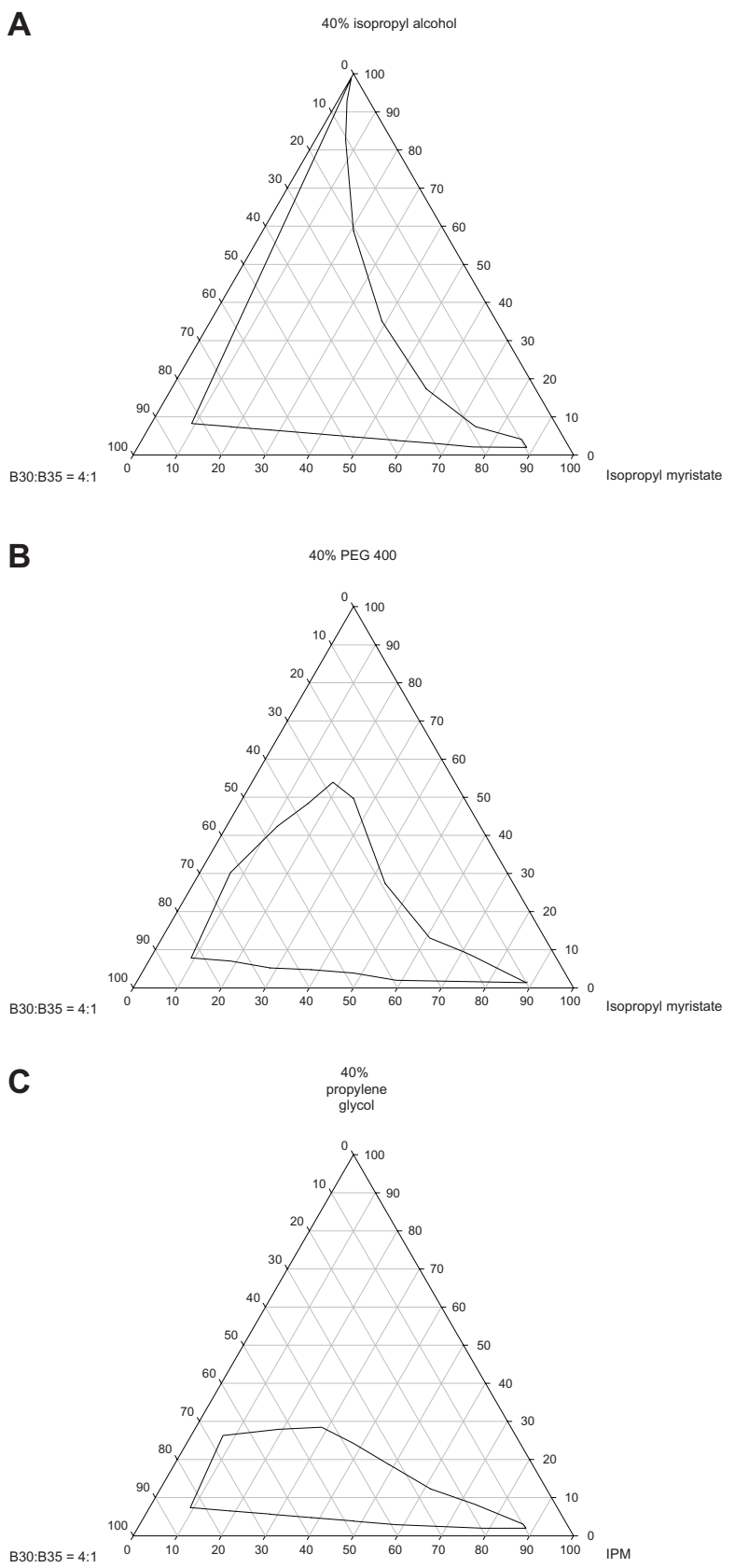

Figure I Pseudoternary phase of microemulsion composed of isopropyl myristate, mixed Brij 30/Brij 35 surfactant and aqueous solution containing $40 \%$ different cosurfactants. Isopropyl alcohol (A), poly(ethylene glycol) (PEG) 400 (B), and propylene glycol (C). Abbreviation: IPM, isopropyl myristate. 
in topical cosmetic and pharmaceutical products. ${ }^{41}$ Moreover, it shows a permeation enhancement effect,,$^{42}$ so it was used as the oil phase. Brij 30 and Brij 35 are nonionic surfactants with reliable biological compatibility, and are also widely used in topical pharmaceutical and cosmetic products. ${ }^{41}$ The hydrophilic-lipophilic balance required for isopropyl myristate was about 11.1. Therefore, the mixed Brij 30/ Brij 35 surfactant was used at a ratio of 4:1 to give a blended hydrophilic-lipophilic balance of about 11.1. Previous studies have reported that a short-chain alkanol cosurfactant can be incorporated into the interfacial layer, resulting in reduced interfacial energy and tension. Cosurfactants can also modify the hydrophilic-lipophilic balance of the surfactant to an appropriate value suitable for formation of a microemulsion. Addition of a cosurfactant can decrease the amount of surfactant needed in a microemulsion. ${ }^{42,43}$
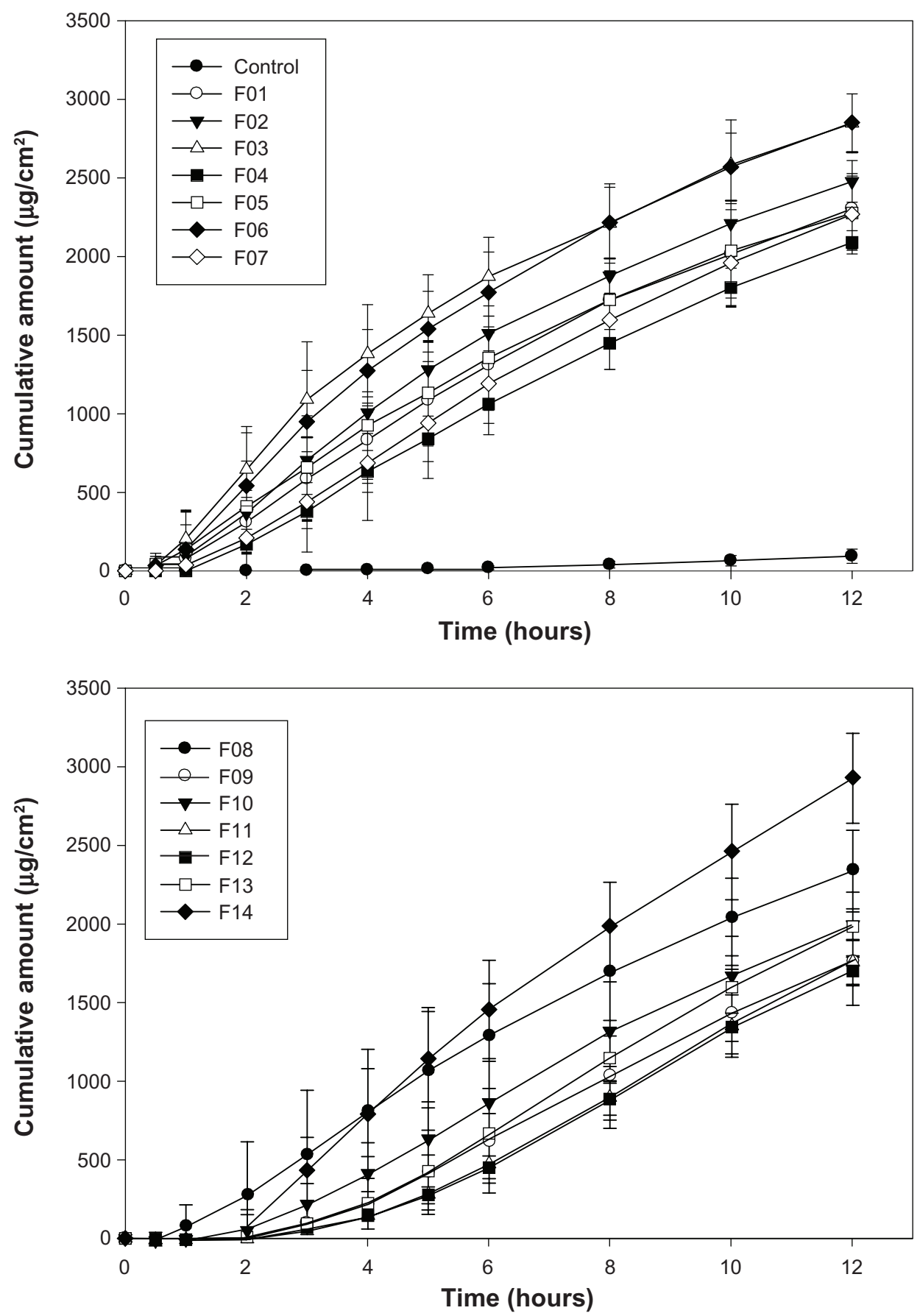

Figure 2 In vitro penetration-time profile of model citalopram formulations and aqueous control of $40 \%$ isopropyl alcohol containing $3 \%$ citalopram through rat skin $(n=3)$. 
The effect of a cosurfactant depends on its chain length; only appropriate chain lengths are suitable for good formation of a microemulsion. ${ }^{44}$ Therefore, three kinds of alkanol, ie, isopropyl alcohol, propylene glycol, and PEG 400, were used in this study to evaluate the effect of cosurfactants on the formation of microemulsions. Pseudoternary phase diagrams were constructed to determine the appropriate compositions of the microemulsions and to evaluate the effect of the cosurfactants. As shown in Figure 1, larger microemulsion regions were obtained when the microemulsion was prepared with isopropyl alcohol. A large microemulsion region gives the investigator the flexibility to vary the ingredients to obtain an appropriate formulation with low surfactant and cosurfactant concentrations and a higher permeation rate. Hence, isopropyl alcohol was used subsequently.

Based on the pseudoternary phase diagrams, the quantitative measures of the independent variables, ie, $\mathrm{X}_{1}$, $X_{2}$, and $X_{3}$, were set at $25 \%-30 \%, 25 \%-30 \%$, and $45 \%-60 \%$, respectively. Various citalopram-loaded microemulsion formulations were prepared according to the constrained mixture design, and their physicochemical properties and permeation parameters were determined.

\section{Physicochemical characteristics of microemulsions}

Droplet size, polydispersity index, and viscosity are shown in Table 1. The droplet size of the model citalopram-loaded microemulsions ranged from $13.2 \mathrm{~nm}$ to $38.0 \mathrm{~nm}$. The polydispersity index ranged from 0.30 to 0.47 . All measurements below 0.5 indicated narrow deviation from the average size. The viscosity of the citalopram-loaded microemulsions ranged from 7.08 to $13.07 \times 10^{3} \mathrm{cps}$ at $37^{\circ} \mathrm{C}$. Our results demonstrate that the combinations in the formulation had a predominant effect on the physicochemical properties of the microemulsions. All the drug-loaded microemulsions remained clear during the in vitro experimental period and at room temperature for more than one year.

\section{Skin permeation study}

The influence of the ingredients in the microemulsions, including the surfactant, cosurfactant, and water mixture on drug penetration capacity was investigated by response surface methodology. Fourteen 3\% citalopram-loaded model microemulsions were prepared and the permeation parameters were determined by in vitro permeation study. An aqueous solution of $40 \%$ isopropyl alcohol containing 3\% citalopram was used as a control to evaluate the enhancement effect of the microemulsions.
The permeation profiles for the model microemulsions and the aqueous control are plotted in Figure 2. Zero-order release kinetics were suitable to fit the curves for all formulations $\left(\mathrm{R}^{2}>0.9920\right)$. The flux $\left(\mu \mathrm{g} / \mathrm{cm}^{2}\right.$ per hour) was calculated. The permeation parameters for all formulations are summarized in Table 1. The flux of the microemulsions ranged from $153.77 \mu \mathrm{g} / \mathrm{cm}^{2}$ to $245.62 \mu \mathrm{g} / \mathrm{cm}^{2}$ per hour, while the lag time ranged from 0.83 hours to 3.0 hours. The wide deviations demonstrate that the permeability of citalopram from the microemulsions was significantly influenced by the composition, ie, proportions of surfactant, cosurfactant, and water in the mixture. The flux and lag time of the aqueous control were $24.2 \pm 2.5 \mu \mathrm{g} / \mathrm{cm}^{2}$ per hour and $6.2 \pm 0.8$ hours, respectively.

When the microemulsion was used as a vehicle, the drug flux increased by 6.4-10.1-fold and the lag time shortened from 6.2 hours to $0.8-3.0$ hours, as compared with the aqueous $40 \%$ isopropyl alcohol solution. These results were in agreement with previous studies ${ }^{45-50}$ reporting that microemulsion systems can increase transdermal drug transport. The mechanism might be attributed to the drug activity in the formulation being promoted by the combined effect of the hydrophilic and lipophilic components of the microemulsion. Further, microemulsions can decrease the interface tension between vehicle and skin, leading to faster permeation. ${ }^{29,51}$

To estimate the quantitative effects of the formulation factor on the permeation parameters of citalopram-loaded microemulsions and to obtain the appropriate formulation, the data collected for responses (flux and lag time) in the model microemulsions were analyzed statistically using response surface methodology and Design-Expert software. The (Stat-Ease Corporation) mathematical polynomial equation to describe the flux may be written as:

$$
\begin{aligned}
\text { Flux }= & 204.3 X_{1}+172.7 X_{2}+167.2 X_{3}+107.1 X_{1} X_{3} \\
& +380.6 X_{2} X_{3}-1380.3 X_{1} X_{2} X_{3}+465.3 X_{1} X_{2}\left(X_{1}-X_{2}\right)
\end{aligned}
$$

The $P$ value for the model equation was less than 0.05 , showing that the model is suitable for describing the relationship between the independent variables and the response. The $P$ value for lack of fit was 0.2331 , showing no indication of significance, which further confirmed the satisfactory fitness of the model. The coefficients for the X term conveyed the intensity of effect of the independent variables.

Coefficients with more than one factor term or higher order term in the regression model polynomial equation represent interaction or quadratic relationships, respectively. The interaction of the three factors showed the highest effect on drug permeation. In the main factor, the surfactant $\left(\mathrm{X}_{1}\right)$ 

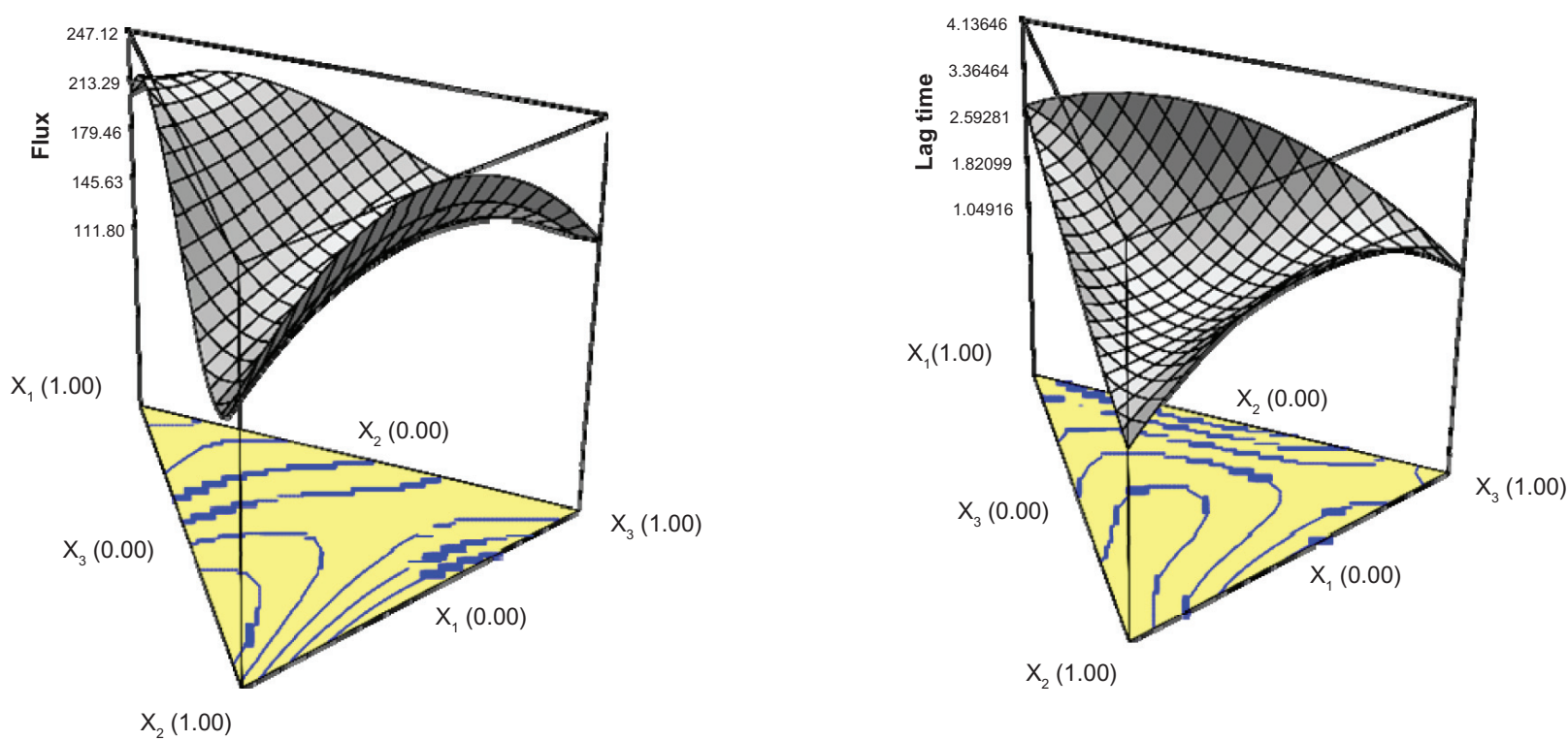

Figure 3 Three-dimensional response surface plots illustrating the effect of surfactant $\left(\mathrm{X}_{1}\right)$, isopropyl alcohol $\left(\mathrm{X}_{2}\right)$, and distilled water $\left(\mathrm{X}_{3}\right)$ on the flux and lag time of citalopram from microemulsions.

showed the greatest effect, followed by the cosurfactant $\left(\mathrm{X}_{2}\right)$ and aqueous phase $\left(\mathrm{X}_{3}\right)$. The response surface plot was constructed to illustrate the relationship between the independent and dependent variables used (Figure 3). Higher flux was observed in microemulsions with specific ratios of surfactant/cosurfactant/aqueous phase (eg, $X_{1}$ at a low level, and $X_{2}$ and $X_{3}$ at a medium level). Surfactants can increase membrane fluidity, drug solubilization, and extraction of lipid from the stratum corneum, resulting in better permeation. ${ }^{52}$ With addition of excess surfactant, the thermodynamic activity of the drug in microemulsion may decrease, leading to decreased drug transport. ${ }^{53}$

The polynomial equation to depict lag time may be written as:

$$
\begin{aligned}
\text { Lag time }= & 2.7 \mathrm{X}_{1}+1.1 \mathrm{X}_{2}+1.5 \mathrm{X}_{3}+4.5 \mathrm{X}_{1} \mathrm{X}_{3} \\
& +5.3 \mathrm{X}_{2} \mathrm{X}_{3}-35.2 \mathrm{X}_{1} \mathrm{X}_{2} \mathrm{X}_{3}
\end{aligned}
$$

The $P$ values of the model and lack of fit were $<0.0001$ and 0.1218 , respectively, indicating that the selected equation can depict the relationship between formulation factors and lag time. The polynomial equation demonstrated that interaction of the three factors had the most significant effect. The surface response plot is shown in Figure 3. It was found that microemulsions with $X_{1}$ and $X_{3}$ at low levels and $X_{2}$ at high levels had a shortened lag time.

Appropriate transdermal microemulsions should have higher flux and shortened lag time simultaneously. The response surface methodology predicted an appropriate formulation with flux and lag time values of $180.23 \mu \mathrm{g} / \mathrm{cm}^{2}$ per hour and 1.60 hours, respectively, when $\mathrm{X}_{1}, \mathrm{X}_{2}$, and $\mathrm{X}_{3}$ values were $0.24,0.23$, and 0.43 , respectively. A new drugloaded microemulsion (F15) was prepared according to these levels of formulation factors to obtain flux and lag time values of $179.63 \pm 20.44 \mu \mathrm{g} / \mathrm{cm}^{2}$ per hour and $1.67 \pm 0.58$ hours, respectively. Observed and predicted values showed no significant difference, indicating that response surface methodology is a potential tool for designing citalopramloaded microemulsions.

In order to increase flux of microemulsion (F15) further, the loading dose was increased from $3 \%$ to $10 \%$. As shown in Figure 4, the flux increased with increasing

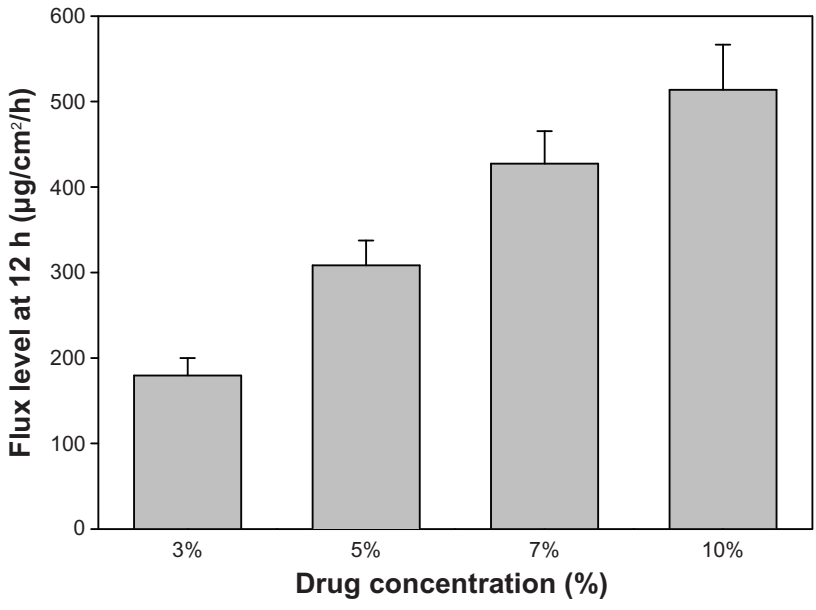

Figure 4 Various concentrations of citalopram in microemulsion (FI5) on flux level per unit area $\left(\mu \mathrm{g} / \mathrm{cm}^{2}\right.$ per hour) from time zero to 12 hours $(n=3)$. 


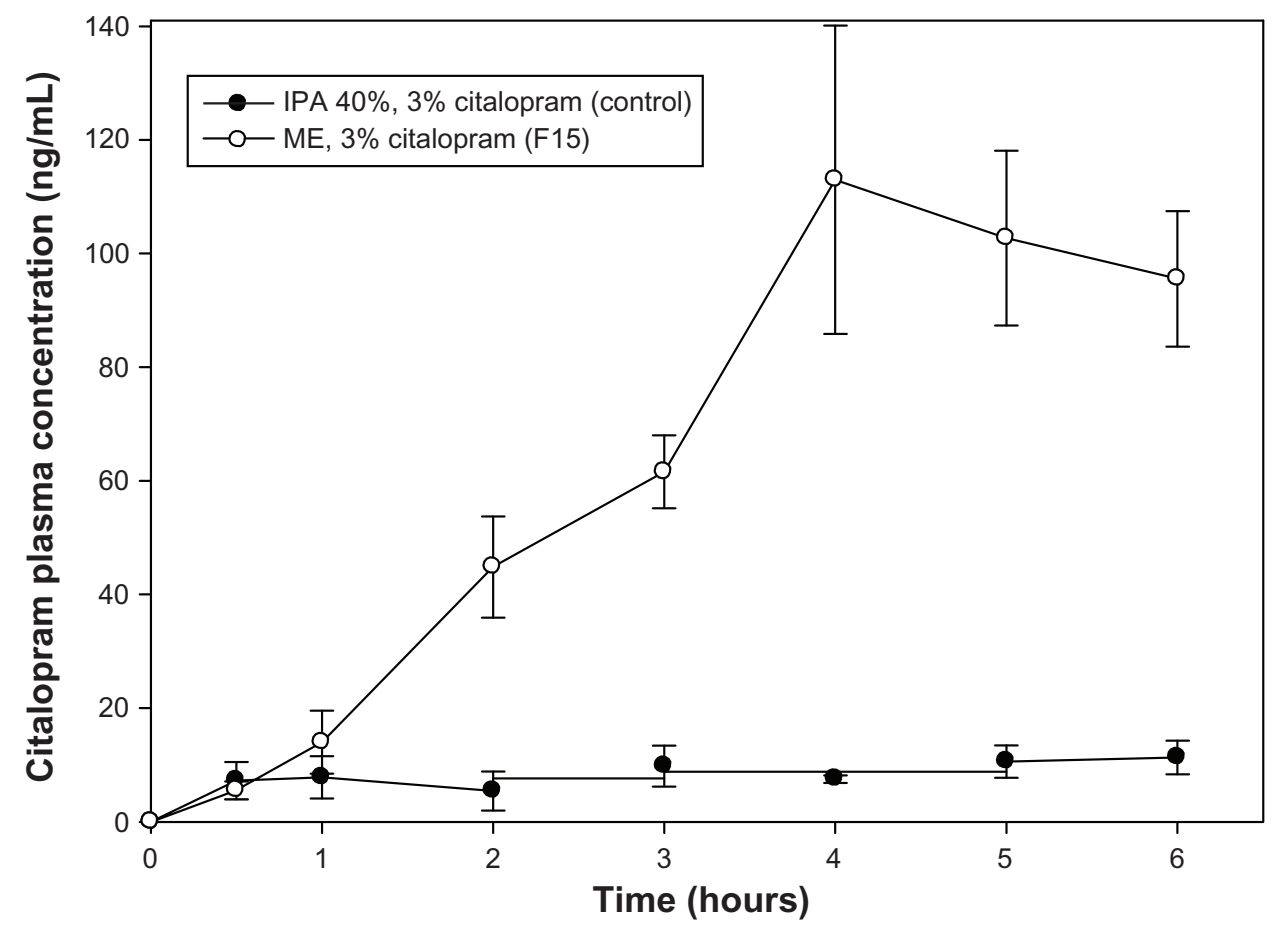

Figure 5 Plasma concentration-time curve for citalopram in rats after transdermal administration of 3\% citalopram microemulsion (FI5). Note: Each sample point represents the mean of three experiments (mean \pm standard error of the mean).

Abbreviations: IPA, isopropyl alcohol; ME, microemulsion.

drug concentration. The flux levels were $179.6 \pm 20.4$, $308.4 \pm 29.1,427.3 \pm 38.1$, and $513.8 \pm 52.8 \mu \mathrm{g} / \mathrm{cm}^{2}$ per hour for $3 \%, 5 \%, 7 \%$, and $10 \%$ citalopram-loaded microemulsions, respectively, showing a linear relationship over the loading dose range of $3 \%-10 \%\left(\mathrm{R}^{2}>0.9817\right)$.

Previous studies ${ }^{1,2}$ reported that the $\mathrm{C}_{\text {max }}$ was $34.42-46.2 \mathrm{ng} / \mathrm{mL}$, and the total body clearance of citalopram was about $0.457 \mathrm{~L} / \mathrm{kg}$ per hour after oral administration of a $40 \mathrm{mg}$ dose. Thus, if the transdermal permeation of human skin for citalopram from the microemulsion (F15) is similar to that of rat skin, the flux required from the citalopramloaded microemulsions is about $1280 \mu \mathrm{g}$ per hour. The area of administration required for the citalopram-loaded microemulsion to obtain a minimum effective therapeutic concentration was 7.1, 4.2, 3.0, and $2.5 \mathrm{~cm}^{2}$, respectively, and these values are in the practical range for topical application.

\section{In vivo animal study}

The in vivo transdermal study result is shown in Figure 5, indicating that the predicted optimized formulation (F15) provided an area under the concentration-time curve $\left(\mathrm{AUC}_{0-6}\right)$ of about $402.59 \pm 74.39 \mathrm{ng} \cdot \mathrm{hr} / \mathrm{mL}$, which is 10 -fold higher than for the controlled formulation (isopropyl alcohol $40 \%, 39.40 \pm 10.10 \mathrm{ng} \cdot \mathrm{hr} / \mathrm{mL}$ ). The $\mathrm{C}_{\max }$ for $\mathrm{F} 15$ is $112.97 \mathrm{ng} / \mathrm{mL}$ and the $\mathrm{T}_{\max }$ is at 4 hours. F15 reached the minimum effective therapeutic concentration $(44.84 \pm 15.45 \mathrm{ng} / \mathrm{mL})$ in less than 2 hours after transdermal administration, indicating potentially adequate efficacy for the treatment of depression in the future.

\section{Skin irritation study}

The irritation test was estimated by the changing level in $\mathrm{L}^{*}$ (white-black index) and a* (red-green index, Table 2).

Table 2 Color difference in rat skin treated with microemulsions containing different amounts of citalopram at different time points as measured by colorimetry

\begin{tabular}{|c|c|c|c|c|c|}
\hline & \multirow[t]{2}{*}{ Control } & \multicolumn{2}{|l|}{2 hours } & \multicolumn{2}{|l|}{6 hours } \\
\hline & & Citalopram $0 \%$ & Citalopram 3\% & Citalopram 0\% & Citalopram 3\% \\
\hline$L^{*}$ & $66.96 \pm 2.32$ & $62.95 \pm 2.06$ & $68.72 \pm 0.95$ & $62.40 \pm 0.80$ & $67.62 \pm 0.94$ \\
\hline$a^{*}$ & $4.65 \pm 0.88$ & $7.87 \pm 2.74$ & $5.44 \pm 0.85$ & $8.56 \pm 1.93$ & $6.65 \pm 1.92$ \\
\hline$b^{*}$ & $1.62 \pm 1.53$ & $2.31 \pm 0.36$ & $-1.74 \pm 1.03$ & $1.35 \pm 0.64$ & $-2.27 \pm 0.56$ \\
\hline
\end{tabular}

Notes: Control, untreated rat skin site. L*, white-black index; $a^{*}$, red-green index; b*, yellow-blue index. All four groups of formulations showed no significant difference in $L^{*}$ (white-black index) or a* (red-green index) compared with untreated skin near attachment site. All data represent the mean of three experiments. 
Both microemulsion formulations (containing $0 \%$ or $3 \%$ of citalopram) showed no significant difference in $\mathrm{L}^{*}$ or $\mathrm{a}^{*}$ at 6 hours, meaning that there is no erythematous reaction even after the formulation reaches the minimum effective therapeutic concentration for citalopram..$^{40,54,55}$

\section{Conclusion}

The permeation rate of citalopram from microemulsions was conspicuously increased and the lag times were also shortened. The compositional proportions in the microemulsion are important in determining the efficacy of the microemulsion as a drug transdermal delivery system. Response surface methodology is a potential tool for investigating the influence of independent variables on dependent variables (responses) and for obtaining an appropriate formulation. The flux of experimental citalopram-loaded microemulsions is expected to provide adequate therapeutic efficacy in a workable application area. Throughout the in vivo study, the formulation was able to reach therapeutic plasma levels, and is worthy of investigation as a transdermal antidepressant drug delivery system.

\section{Disclosure}

The authors report no conflicts of interest in this work.

\section{References}

1. Gutierrez MM, Abramowitz W. Pharmacokinetic comparison of oral solution and tablet formulations of citalopram: a single-dose, randomized, crossover study. Clin Ther. 2000;22(12):1525-1532.

2. Mendoza L, Hajduch M, Kekulova H, Svobodova X, Mihal V, Svoboda M. Bioequivalence of two brands of citalopram $40 \mathrm{mg}$ tablets after single oral administration to healthy volunteers. Biomed Pap Med Fac Univ Palacky Olomouc Czech Repub. 2005;149(1):169-172.

3. Suresh PS, Giri S, Husain R, Mullangi R. A highly sensitive LC-MS/ MS method for the determination of S-citalopram in rat plasma: application to a pharmacokinetic study in rats. Biomed Chromatogr. 2010;24(10):1052-1058.

4. Milne RJ, Goa KL. Citalopram. A review of its pharmacodynamic and pharmacokinetic properties, and therapeutic potential in depressive illness. Drugs. 1991;41(3):450-477.

5. Rang HP. Pharmacology. Edinburgh, UK: Churchill Livingstone; 2003.

6. Uptodate. 2012. http://www.uptodate.com/contents/citalopram-druginformation.

7. Rohrs S, Geiser F, Conrad R. Citalopram-induced subacute cutaneous lupus erythematosus - first case and review concerning photosensitivity in selective serotonin reuptake inhibitors. Gen Hosp Psychiatry. 2012; 34(5):541-545.

8. Vandenberg CM. MAOIs and transdermal delivery. J Clin Psychiatry. 2012;73(9):e28.

9. VanDenBerg CM. The transdermal delivery system of monoamine oxidase inhibitors. J Clin Psychiatry. 2012;73 Suppl 1:25-30.

10. Patkar AA, Pae CU, Zarzar M. Transdermal selegiline. Drugs Today (Barc). 2007;43(6):361-377.

11. Kim HM, Lim YY, An JH, Kim MN, Kim BJ. Transdermal drug delivery using disk microneedle rollers in a hairless rat model. Int J Dermatol. 2012;51(7):859-863.

12. Nair A, Vyas H, Shah J, Kumar A. Effect of permeation enhancers on the iontophoretic transport of metoprolol tartrate and the drug retention in skin. Drug Deliv. 2011;18(1):19-25.
13. Ryan E, Garland MJ, Singh TR, et al. Microneedle-mediated transdermal bacteriophage delivery. Eur J Pharm Sci. 2012;47(2): 297-304.

14. Tsai YH, Chang JT, Huang CT, Chang JS, Huang YB, Wu PC. Electrically-assisted skin delivery of buspirone submicron emulsions. J Food Drug Anal. 2012;20:22-26.

15. Vaghani SS, Gurjar M, Singh S, et al. Effect of iontophoresis and permeation enhancers on the permeation of an acyclovir gel. Curr Drug Deliv. 2010;7(4):329-333.

16. Azeem A, Ahmad FJ, Khar RK, Talegaonkar S. Nanocarrier for the transdermal delivery of an antiparkinsonian drug. AAPS PharmSciTech. 2009;10(4):1093-1103.

17. Chen Y, Wu Q, Zhang Z, Yuan L, Liu X, Zhou L. Preparation of curcumin-loaded liposomes and evaluation of their skin permeation and pharmacodynamics. Molecules. 2012;17(5):5972-5987.

18. Fang JY, Leu YL, Chang CC, Lin CH, Tsai YH. Lipid nano/submicron emulsions as vehicles for topical flurbiprofen delivery. Drug Deliv. 2004;11(2):97-105.

19. Fang YP, Huang YB, Wu PC, Tsai YH. Topical delivery of 5-aminolevulinic acid-encapsulated ethosomes in a hyperproliferative skin animal model using the CLSM technique to evaluate the penetration behavior. Eur J Pharm Biopharm. 2009;73(3):391-398.

20. Shi J, Ma F, Wang X, Wang F, Liao H. Formulation of liposomes gels of paeonol for transdermal drug delivery by Box-Behnken statistical design. J Liposome Res. 2012;22(4):270-278.

21. Zhu W, Yu A, Wang W, Dong R, Wu J, Zhai G. Formulation design of microemulsion for dermal delivery of penciclovir. Int J Pharm. 2008; 360(1-2):184-190.

22. Kim BS, Won M, Lee KM, Kim CS. In vitro permeation studies of nanoemulsions containing ketoprofen as a model drug. Drug Deliv. 2008;15(7):465-469.

23. Wang L, Dong J, Chen J, Eastoe J, Li X. Design and optimization of a new self nanoemulsifying drug delivery system. J Colloid Interface Sci. 2009;330(2):443-448.

24. Wu H, Ramachandran C, Weiner ND, Roessler BJ. Topical transport of hydrophilic compounds using water-in-oil nanoemulsions. Int J Pharm. 2001;220(1-2):63-75.

25. Heuschkel S, Goebel A, Neubert RH. Microemulsions - modern colloidal carrier for dermal and transdermal drug delivery. $J$ Pharm Sci. 2008;97(2):603-631.

26. Abramovic Z, Sustarsic U, Teskac K, Sentjurc M, Kristl J. Influence of nanosized delivery systems with benzyl nicotinate and penetration enhancers on skin oxygenation. Int J Pharm. 2008;359(1-2): 220-227.

27. Bolzinger MA, Briancon S, Pelletier J, Fessi H, Chevalier Y. Percutaneous release of caffeine from microemulsion, emulsion and gel dosage forms. Eur J Pharm Biopharm. 2008;68(2):446-451.

28. Fini A, Bergamante V, Ceschel GC, Ronchi C, De Moraes CA. Control of transdermal permeation of hydrocortisone acetate from hydrophilic and lipophilic formulations. AAPS PharmSciTech. 2008; 9(3):762-768.

29. Teichmann A, Heuschkel S, Jacobi U, et al. Comparison of stratum corneum penetration and localization of a lipophilic model drug applied in an o/w microemulsion and an amphiphilic cream. Eur J Pharm Biopharm. 2007;67(3):699-706.

30. Aktas E, Eroglu H, Kockan U, Oner L. Systematic development of $\mathrm{pH}$-independent controlled release tablets of carvedilol using central composite design and artificial neural networks. Drug Dev Ind Pharm. July 18, 2012. Epub 2012 July 18

31. Chaudhary H, Kohli K, Amin S, Rathee P, Kumar V. Optimization and formulation design of gels of diclofenac and curcumin for transdermal drug delivery by Box-Behnken statistical design. J Pharm Sci. 2011; 100(2):580-593.

32. Gannu R, Palem CR, Yamsani SK, Yamsani VV, Yamsani MR. Enhanced bioavailability of buspirone from reservoir-based transdermal therapeutic system, optimization of formulation employing Box-Behnken statistical design. AAPS PharmSciTech. 2010;11(2):976-985. 
33. Hao J, Wang F, Wang X, et al. Development and optimization of baicalinloaded solid lipid nanoparticles prepared by coacervation method using central composite design. Eur J Pharm Sci. July 20, 2012. Epub 2012 July 20.

34. Makraduli L, Crcarevska MS, Geskovski N, Dodov MG, Goracinova K. Factorial design analysis and optimisation of alginate-Ca-chitosan microspheres. J Microencapsul. 2013;30(1):81-92.

35. Malzert-Freon A, Hennequin D, Rault S. Partial least squares analysis and mixture design for the study of the influence of composition variables on lipidic nanoparticle characteristics. J Pharm Sci. 2010; 99(11):4603-4615.

36. Pabari RM, Ramtoola Z. Application of face centred central composite design to optimise compression force and tablet diameter for the formulation of mechanically strong and fast disintegrating orodispersible tablets. Int J Pharm. 2012;430(1-2):18-25.

37. Lewis GA, Mathieu D, Phan-Tan-Luu R. Pharmaceutical Experimental Design. New York, NY: Dekker; 1999.

38. Macek J, Ptacek P, Klima J. Rapid determination of citalopram in human plasma by high-performance liquid chromatography. J Chromatogr B Biomed Sci Appl. 2001;755(1-2):279-285.

39. Mendoza L, Hajduch M, Kekulova H, Svobodova X, Mihal V, Svoboda M. Bioequivalence of two brands of citalopram $40 \mathrm{mg}$ tablets after single oral administration to healthy volunteers. Biomed Pap Med Fac Univ Palacky Olomouc Czech Repub. 2005;149(1):169-172.

40. Fang JY, Tsai MJ, Huang YB, Wu PC, Tsai YH. Percutaneous absorption and skin erythema: quantification of capsaicin and its synthetic derivatives from gels incorporated with benzalkonium chloride by using non-invasive bioengineering methods. Drug Dev Res. 1997;40: 56-67.

41. Kibbe AH. Handbook of Pharmaceutical Excipients, 3rd ed. London, UK: Pharmaceutical Press; 2000.

42. Peltola S, Saarinen-Savolainen P, Kiesvaara J, Suhonen TM, Urtti A. Microemulsions for topical delivery of estradiol. Int J Pharm. 2003; 254(2):99-107.

43. El Maghraby GM. Transdermal delivery of hydrocortisone from eucalyptus oil microemulsion: effects of cosurfactants. Int J Pharm. 2008;355(1-2):285-292.
44. Ho HO, Hsiao CC, Sheu MT. Preparation of microemulsions using polyglycerol fatty acid esters as surfactant for the delivery of protein drugs. J Pharm Sci. 1996;85(2):138-143.

45. Bouchemal K, Briancon S, Perrier E, Fessi H. Nano-emulsion formulation using spontaneous emulsification: solvent, oil and surfactant optimisation. Int J Pharm. 2004;280(1-2):241-251.

46. Lee PJ, Langer R, Shastri VP. Novel microemulsion enhancer formulation for simultaneous transdermal delivery of hydrophilic and hydrophobic drugs. Pharm Res. 2003;20(2):264-269.

47. Paolino D, Ventura CA, Nistico S, Puglisi G, Fresta M. Lecithin microemulsions for the topical administration of ketoprofen: percutaneous adsorption through human skin and in vivo human skin tolerability. Int J Pharm. 2002;244(1-2):21-31.

48. Tsai YH, Lee KF, Huang YB, Huang CT, Wu PC. In vitro permeation and in vivo whitening effect of topical hesperetin microemulsion delivery system. Int J Pharm. 2010;388(1-2):257-262.

49. Wu H, Ramachandran C, Bielinska AU, et al. Topical transfection using plasmid DNA in a water-in-oil nanoemulsion. Int J Pharm. 2001; 221(1-2):23-34.

50. Yuan Y, Li SM, Mo FK, Zhong DF. Investigation of microemulsion system for transdermal delivery of meloxicam. Int J Pharm. 2006; 321(1-2):117-123.

51. Schmalfuß U, Neubert R, Wohlrab W. Modification of drug penetration into human skin using microemulsions. J Control Release. 1997;46: 279-285.

52. Rege BD, Kao JP, Polli JE. Effects of nonionic surfactants on membrane transporters in Caco-2 cell monolayers. Eur J Pharm Sci. 2002; 16(4-5):237-246.

53. Rhee YS, Choi JG, Park ES, Chi SC. Transdermal delivery of ketoprofen using microemulsions. Int J Pharm. 2001;228(1-2):161-170.

54. Hoffmann K, Auer T, Stucker M, Dirschka T, el-Gammal S, Altmeyer P. Evaluation of the efficacy of $\mathrm{H} 1$ blockers by noninvasive measurement techniques. Dermatology. 1994;189(2):146-151.

55. Serup J, Agner T. Colorimetric quantification of erythema - a comparison of two colorimeters (Lange Micro Color and Minolta Chroma Meter CR-200) with a clinical scoring scheme and laserDoppler flowmetry. Clin Exp Dermatol. 1990;15(4):267-272.
International Journal of Nanomedicine

\section{Publish your work in this journal}

The International Journal of Nanomedicine is an international, peerreviewed journal focusing on the application of nanotechnology in diagnostics, therapeutics, and drug delivery systems throughout the biomedical field. This journal is indexed on PubMed Central, MedLine, CAS, SciSearch $\AA$, Current Contents ${ }^{\circledR} /$ Clinical Medicine,

\section{Dovepress}

Journal Citation Reports/Science Edition, EMBase, Scopus and the Elsevier Bibliographic databases. The manuscript management system is completely online and includes a very quick and fair peer-review system, which is all easy to use. Visit http://www.dovepress.com/ testimonials.php to read real quotes from published authors. 